\title{
Esophageal rupture: a severe complication of transesophageal echocardiography
}

Fernando Peixoto Ferraz de Campos ${ }^{a}$, Brenda Margatho Ramos Martines ${ }^{b}$, João Augusto dos Santos Martines ${ }^{b}$, José de Arimatéia Batista Araújo Filho ${ }^{c}$

Campos FPF, Martines BMR, Martines JAS, Araújo Filho JAB. Esophageal rupture: a severe complication of transesophageal echocardiography. Autopsy Case Rep [Internet]. 2012;2(3):45-49. http://dx.doi.org/10.4322/ acr.2012.025

\section{ABSTRACT}

Since when the first transesophageal echocardiography (TEE) was undertaken in 1975, technological advances have made this diagnostic modality more reliable. TEE indications became widespread in cardiac and non-cardiac surgeries, intensive care units, and ambulatory clinics. The procedure is generally considered a safe diagnostic tool, but occasionally complications do occur. The insertion and manipulation of the ultrasound probe can cause oropharyngeal, esophageal, or gastric trauma. Although rare, these complications may present a mortality rate of up to $56 \%$ depending on the treatment approach and the elapsed time to the diagnosis. The authors report a case of a 65-year-old woman submitted to attempt a TEE in order to better study or diagnose an inter-atrial communication. After 3 days of the procedure, the patient was admitted to the hospital with edema, hyperemia of the anterior face of the neck, accompanied by systemic symptoms. The imaging diagnostic work-up evidenced signs of esophageal rupture and upper mediastinal involvement, the former confirmed by upper gastrointestinal endoscopy. The patient was treated with antibiotics and cervical and mediastinal drainage, with a favorable outcome.

Keywords: Echocardiography, transesophageal; Mediastinitis; Esophagus; latrogenic disease.

\section{CASE REPORT}

A 65-year-old female patient, diagnosed with diabetes mellitus and systemic arterial hypertension, underwent a transesophageal echocardiography (TEE) for a suspected diagnosis of atrial septal defect. The procedure was performed without sedation under topical anesthesia. After three attempts, the procedure was interrupted due to difficulties in progression of the probe into the esophagus, accompanied by retching and an inability by the patient to collaborate with the exam performance.

At the end of the examination attempts, the patient immediately experienced neck and oropharyngeal pain. Four hours later she complained of severe dysphagia. On the next day, she noticed edema and hyperemia throughout the anterior neck surface, local pain, and systemic

\footnotetext{
a Department of Internal Medicine - Hospital Universitário - Universidade de São Paulo, São Paulo/SP - Brazil.

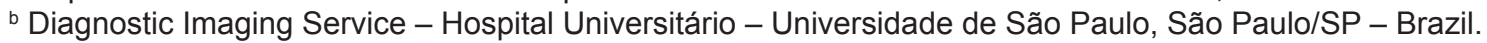

${ }^{c}$ Heart Institute - Hospital das Clínicas - Faculdade de Medicina - Universidade de São Paulo, São Paulo/SP - Brazil.
}

Copyright $\odot 2012$ Autopsy and Case Reports - This is an Open Access article distributed of terms of the Creative Commons Attribution NonCommercial License (http://creativecommons.org/licenses/by/3.0/) which permits unrestricted non-commercial use, distribution, and reproduction in any médium provided article is properly cited. 
symptoms like weakness and malaise. On the third day she was admitted at the hospital. On physical examination she looked well; her blood pressure was $150 / 100 \mathrm{mmHg}$ and pulse rate was 100 beats per minute. Edema and hyperemia were evident on the anterior neck surface from the chin up to $3 \mathrm{~cm}$ below the furculum where subcutaneous emphysema was also palpable. The oropharynx examination showed intense hyperemia. A computed tomography (CT) scan of the neck showed subcutaneous emphysema in the mediastinal, supraclavicular, and retroesophageal space, which originated from a fistula of the posterior esophageal wall at C6-C7 level (Figures 1 and 2). Upper gastrointestinal endoscopy revealed a marked vascular congestion and edema of the hypopharynx, which progressed to the pyriform sinuses and upper esophageal sphincter, hindering the examination. Passing through the obstruction, just below the cricopharyngeal muscle, a $2 \mathrm{~cm}$ perforation of the esophageal wall was evidenced, where a purulent secretion was draining. The remaining endoscopic examination was normal. Facing the diagnosis of esophageal injury with mediastinal involvement, ceftriaxone and clindamycin was initiated and cervicotomy was carried out allowing the drainage of a large amount of pus from the upper mediastinum and periesophageal space. The patient presented with septic shock immediately postoperatively, requiring norepinephrine for hemodynamic stabilization as well as mechanical ventilatory support. After a week of intensive care the clinical status improved with an esophageal fistula remaining.

\section{DISCUSSION}

Since the first TEE examination in 1975, many technical advances in equipment have occurred resulting in better quality information than that from transthoracic echocardiography. ${ }^{1}$ With advancing technology and greater experience of echocardiographers, the number of clinical applications and the scope of TEE has increased.

TEE became a standard intraoperative diagnostic technique for the management of patients undergoing cardiac surgery ${ }^{2,3}$ as well as other major surgical procedures; for example, lung transplantation, liver transplantation, and aortic surgery. ${ }^{4}$ In addition, patients in intensive care units (ICUs) or emergency rooms with cardiovascular disease in a non-operative setting, may profit from the diagnostic information. ${ }^{4,5}$

The procedure is generally considered a safe diagnostic tool, but complications associated with transesophageal echocardiography can occur. The insertion and manipulation of the ultrasound

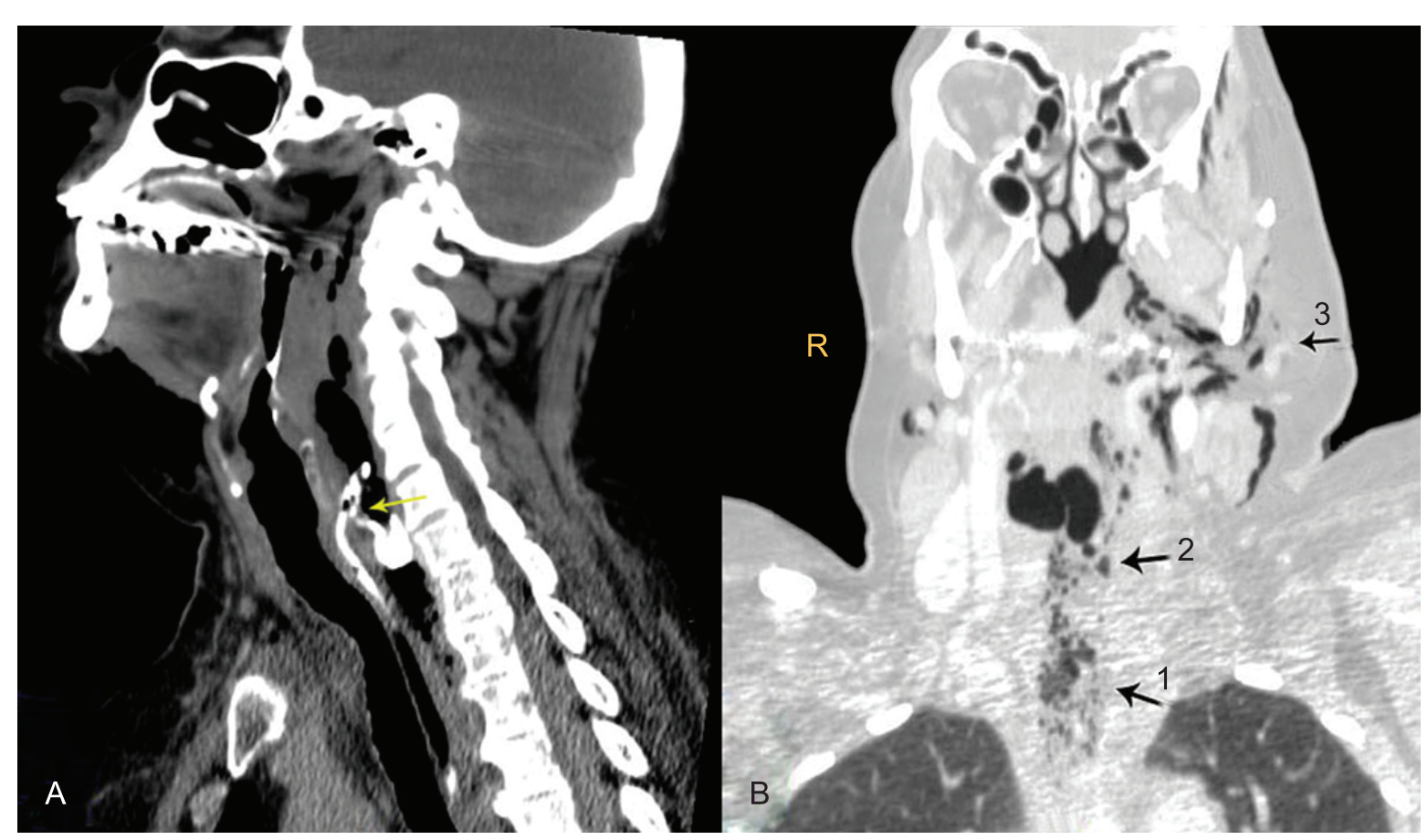

Figure 1 - CT of the neck. A - Sagittal plane showing the esophageal fistula demonstrated by the extravasation of oral contrast to the retropharyngeal space (arrow); $\mathbf{B}$ - Coronal plane showing extension of the emphysema to the deep layers of the upper thoracic entrance (arrow 1) to the parapharyngeal (arrow 2) and masticator muscles (arrow 3). 


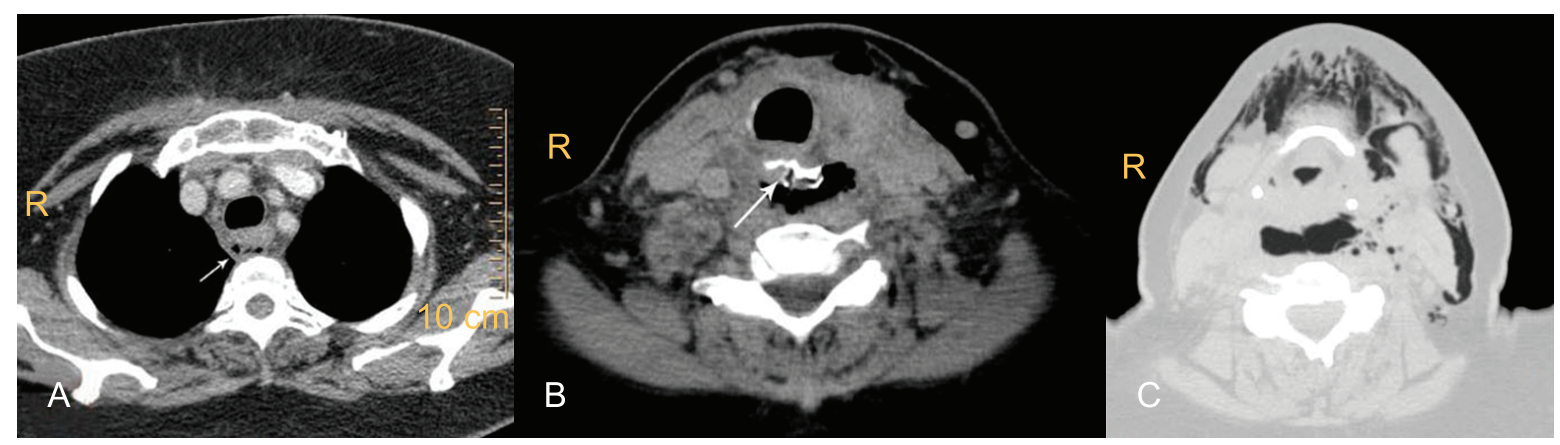

Figure 2-Axial CT of the neck. A - Mild emphysema and densification of fat planes in the upper mediastinum (arrow); B - Extravasation of oral contrast to the retropharyngeal space (arrow); C - Presence of emphysema in the deep neck spaces, retropharyngeal, masticator, and submandibular.

probe can cause oropharyngeal, esophageal, or gastric trauma.

A systematic review of the literature between 1975 and 2007 retrieved 207 articles pairing "transesophageal echocardiography" with complications-related words. This review comprised 17 adult and 1 pediatric databases, representing 42,355 patients and 1,650 patients, respectively. A total of 30 reports of patients with perforations and 14 patients with bleeding constituted the most serious complications. ${ }^{6}$ Other studies reported major TEE complication rates between $0.01 \%$ and $0.04 \%,{ }^{7-9}$ although higher rates were reported for ambulatory (non-operative) settings ranging from $0.2 \%$ to $0.5 \%$, and for intraoperative TEE ranging from 0.2 to $1.2 \%{ }^{4}$

Retching, which occurs in about $39 \%$ of subjects who are awake and submitted to TEE, contributes to premature termination of the procedure. In these cases, examinations should not be pursued. Occult gastroesophageal lesions and anatomic changes, which are more common among the elderly, are risk factors for complications associated with TEE. Diverticula, mechanical impairment of the cervical spine due to arthritis, hiatal hernia (regardless the presence of esophagitis), Schatzki's ring, prior cervical surgery, neoplasm or inflammatory mucosal changes, esophageal achalasia, late scleroderma, Barrett's esophagus, are among these risk factors. ${ }^{8-10,11}$ Normal anatomical variants, such as aortic impression, large left atrium and left main bronchus, as well as enlarged heart and mediastinal tumor, may impair the TEE performance, thereby constituting risk factors for TEE complications as well. ${ }^{6}$

In general, esophageal perforation occurs predominantly in the cervical portion of the organ
$(54.5 \%)$ and less frequently in the abdominal area $(9.1 \%) .{ }^{12}$ Saphir et al. stated that the hypopharynx and upper esophagus are regions most vulnerable to perforation because an intrinsic weakness of the esophageal wall. ${ }^{13}$

When sedated or under topical anesthesia for TEE, major complications promptly become evident from signs of subcutaneous emphysema, dyspnea, and pain, while under general anesthesia the perforation goes unnoticed. Such occult iatrogenic lesion may result in mediastinitis, septic shock, and multisystem organ failure. ${ }^{14-16}$ This dramatic outcome causes prolonged hospitalization and is related to a mortality rate of $10-56 \%$ depending on the mode of management (surgical vs clinical) and time to diagnosis., ${ }^{4,17}$ In the review conducted by Côté and Denault, the reports, in which bleeding was the major complication, showed higher mortality compared with the ones where perforation was the main injury. ${ }^{6}$

Diagnosis, when clinically suspected, can be confirmed either by endoscopy, CT, and upright position chest radiographs. The most frequent findings include: pneumothorax, pleural effusion, empyema, air/fluid levels, mediastinal shifts, and subcutaneous emphysema. ${ }^{6}$ Mediastinitis and purulent collection can be detected a few days after the injury, as in the case reported here. One must be aware that in a study of esophageal perforation from all causes, up to $33 \%$ of initial chest radiographs were normal ${ }^{18}$, therefore the diagnosis work-up, when TEE complication is suspected, should never be based solely in the chest $x$-ray.

Still in the spectrum of TEE complications, minor bleeding related to mucosal trauma, ulcerative processes, dysphagia, hoarseness, sore throat, laryngeal palsy, tongue and lip injuries are included. 
Cardiovascular complications are also related to TEE and comprise vagal and sympathetic reflexes, such as hypertension or hypotension, tachyarrhythmia or bradycardia, as well as angina and myocardial ischemia. The incidence of cardiovascular complications reported in a multicenter European study was $0.8 \%,{ }^{7}$

Thermal injury can occur when the probe generates excessive heat. To prevent such injuries, when the temperature exceeds $40^{\circ} \mathrm{C}$ a sensor in the probe shuts down the system. ${ }^{6}$

Under normal conditions, if the patient has a mass in the right atrium, the chance of dislodging it during TEE is minimal. ${ }^{6}$ However, retching and coughing increases intrathoracic pressure. This pressure variation, which occurs during the procedure, may cause mobilization of any intracardiac material. ${ }^{19}$ It has been reported that large intrathoracic pressures and hemodynamic changes resulting from retching have produced fatal pulmonary embolization from a right atrial mass, embolization of mitral vegetation, and a left intracardiac thrombus resulting in stroke. ${ }^{20,21}$

Aviv et al. showed a substantial decrease of complications during TEE when the probe passage is performed under direct visualization by trans-nasal video-endoscopy monitoring the hypopharynx. ${ }^{22}$

In the case reported here, the examination attempts, done under topical anesthesia, resulted in retching by the patient as well as her incapacity to collaborate with the probe insertion. No anatomical variation or lesion was detected by the endoscopy performed afterwards. Fortunately, the patient sought medical attention within a timeframe that permitted a correct diagnosis, which resulted in a favorable outcome.

This case report illustrates that even a diagnostic technique that is considered by some to be safe and relatively non-invasive ${ }^{4}$ is associated with dramatic and life threatening complications, which is a warning to general practitioners, cardiologists, and echocardiographers.

\section{REFERENCES}

1. Gautam PL, Aslam N. Transesophageal echocardiography and the anaesthesiologist. 2001 [cited 2012 August 2].
Available from: http://www.theiaforum.org/Article_Folder/ transesophageal-echocardiography-anaesthesiologist.pdf

2. Click RL, Abel MD, Schaff HV. Intraoperative transesophageal echocardiography: 5-year prospective review of impact on surgical management. Mayo Clin Proc. 2000;75:241-7. PMid:10725949.

3. Eltzschig HK, Rosenberger P, Loffler M, Fox JA, Aranki SF, Shernan SK. Impact of intraoperative transesophageal echocardiography on surgical decisions in 12,566 patients undergoing cardiac surgery. Ann Thorac Surg. 2008;85:845-52. PMid:18291154. http://dx.doi. org/10.1016/j.athoracsur.2007.11.015

4. Hilberath JN, Oakes DA, Shernan SK, et al. Safety of transesophageal echocardiography. J Am Soc Echocardiogr. 2010;23:1115-27.

5. Hüttemann E.Tranesophageal echocardiography in critical care. Minerva Anestesiol. 2006;72:891-913. PMid:17095988.

6. Côté GA, Denault A. Transesophageal echocardiographyrelated complications Can J Anesth. 2008;55:622-47.

7. Daniel WG, Erbel R, Kasper W, et al. Safety of transesophageal echocardiography. A multicenter survey of 10,419 examinations. Circulation. 1991;83:817-21. PMid:1999032. http://dx.doi.org/10.1161/01.CIR.83.3.817

8. Kallmeyer IJ, Collard CD, Fox JA, Body SC, Shernan SK. The safety of intraoperative transesophageal echocardiography: a case series of 7200 cardiac surgical patients. Anesth Analg. 2001;92:1126-30. PMid:11323333. http://dx.doi. org/10.1097/00000539-200105000-00009

9. LennonMJ, Gibbs NM, WeightmanWN, Leber J, Ee HC, Yusoff IF.Transesophageal echocardiography-related gastrointestinal complications in cardiac surgical patients. J Cardiothorac Vasc Anesth. 2005;19:141-5. PMid:15868517. http://dx.doi. org/10.1053/j.jvca.2005.01.020

10. Vignon P, Gueret P, Chabernaud JM, et al. [Failure and complications of transesophageal echocardiography. Apropos of 1500 consecutive cases]. Arch Mal Coeur Vaiss. 1993;86:849-55. French. PMid:8274056.

11. Tam JW, Burwash IG, Ascah KJ, et al. Feasibility and complications of single-plane and biplane versus multiplane transesophageal imaging: a review of 2947 consecutive studies. Can J Cardiol. 1997;13:81-4. PMid:9039070.

12. Fernandez FF, Richter A, Freudenberg S, Wendl K, Manegold BC. Treatment of endoscopic esophageal perforation. Surg Endosc. 1999;13:962-6. PMid:10526027. http://dx.doi. org/10.1007/s004649901147

13. 13.Saphir JR, Cooper JA, Kerbavez RJ, Larson SF, Schiller NB. Upper airway obstruction after transesophageal echocardiography. J Am Soc Echocardiogr. 1997;10: 977-8. http://dx.doi.org/10.1016/S0894-7317(97)80015-6 
14. Lalanne B, Dupont M. [Pseudomonas aeruginosa mediastinitis after transesophageal echocardiography]. Presse Med. 1996;25:952. French.

15. Jougon J, Gallon P, Dubrez J, et al. [Esophageal perforation during transesophageal echocardiography]. Arch Mal Coeur Vaiss. 2000;93:1235-7. French. PMid:11107484.

16. Zalunardo MP, Bimmler D, Grob UC, Stocker R, Pasch T, Spahn DR. Late oesophageal perforation after intraoperative transoesophageal echocardiography. $\mathrm{Br} \mathrm{J}$ Anaesth. 2002;88:595-7. PMid:12066742. http://dx.doi. org/10.1093/bja/88.4.595

17. Lawrence DR, Moxon RE, Fountain SW, Ohri SK, Townsend ER. latrogenic oesophageal perforations: a clinical review. Ann R Coll Surg Engl. 1998;80:115-8. PMid:9623376. PMCid:2502991.

18. Flynn AE, Verrier ED, Way LW, Thomas AN, Pellegrini CA. Esophageal perforation. Arch Surg. 1989;124:12115. PMid:2802986. http://dx.doi.org/10.1001/ archsurg.1989.01410100117020
19. Kwak KD, Mosher SF, Willis CL, Kimura BJ. Witnessed embolization of a right atrial mass during transesophageal echocardiography: implications regarding the safety of esophageal intubation. Chest. 1999;115:1462-4. PMid:10334174. http://dx.doi.org/10.1378/chest.115.5.1462

20. Black IW, Cranney GB, Walsh WF, Brender D. Embolization of a left atrial ball thrombus during transesophageal echocardiography. J Am Soc Echocardiogr. 1992;5:271-3. PMid:1622618.

21. Chee TS, Quek SS, Ding ZP, Chua SM. Clinical utility, safety, acceptability and complications of transoesophageal echocardiography (TEE) in 901 patients. Singapore Med J 1995;36:479-83. PMid:8882528.

22. Aviv JE, Di Tulio MR, Homma S, et al. Hypopharyngeal perforation near-miss during transesophageal echocardiography. Laryngoscope. 2004;114:821-6. PMid:15126737. http://dx.doi.org/10.1097/00005537200405000-00006

\section{Conflict of interest: None}

Submitted on: $15^{\text {th }}$ July 2012

Accept on: $14^{\text {th }}$ August 2012

Correspondence: Divisão de Clínica Médica

Av. Prof. Lineu Prestes, 2565 - Cidade Universitária - São Paulo/SP - Brazil

CEP: 05508-000 - Phone: +55 (11) 3091-9200

E-mail: ffcampos@usp.br 
